\title{
Decreased atherosclerosis in $\mathrm{CX}_{3} \mathrm{CR}^{-/-}$mice reveals a role for fractalkine in atherogenesis
}

\author{
Philippe Lesnik, ${ }^{1,2}$ Christopher A. Haskell, ${ }^{1}$ and Israel F. Charo ${ }^{1,3}$ \\ ${ }^{1}$ Gladstone Institute of Cardiovascular Disease, San Francisco, California, USA \\ ${ }^{2}$ Institut National de la Santé et de la Recherche Médicale, Unit 551, Hôpital de la Pitié-Salpetrière, Paris, France \\ ${ }^{3}$ Cardiovascular Research Institute, Department of Medicine, University of California, San Francisco, California, USA
}

The hallmark of early atherosclerosis is the accumulation of lipid-laden macrophages in the subendothelial space. Circulating monocytes are the precursors of these "foam cells," and recent evidence suggests that chemokines play important roles in directing monocyte migration from the blood to the vessel wall. Fractalkine (FK) is a structurally unusual chemokine that can act either as a soluble chemotactic factor or as a transmembrane-anchored adhesion receptor for circulating leukocytes. A polymorphism in the $\mathrm{FK}$ receptor, $\mathrm{CX}_{3} \mathrm{CR} 1$, has been linked to a decrease in the incidence of coronary artery disease. To determine whether FK is critically involved in atherogenesis, we deleted the gene for $\mathrm{CX}_{3} \mathrm{CR} 1$ and crossed these mice into the $a \mathrm{poE}^{-/-}$background. Here we report that $\mathrm{FK}$ is robustly expressed in lesional smooth muscle cells, but not macrophages, in $a p o E^{-/}$mice on a highfat diet. $\mathrm{CX}_{3} \mathrm{CR}^{-/-}$mice have a significant reduction in macrophage recruitment to the vessel wall and decreased atherosclerotic lesion formation. Taken together, these data provide strong evidence that FK plays a key role in atherogenesis.

This article was published online in advance of the print edition. The date of publication is available

from the JCI website, http://www.jci.org. J. Clin. Invest. 111:333-340 (2003). doi:10.1172/JCI200315555.

\section{Introduction}

Monocyte infiltration of the vessel wall is an early and essential step in atherogenesis (1-3), but the signals that recruit and activate monocytes/macrophages are not well understood. Fractalkine ( $\left.\mathrm{FK}, \mathrm{CX}_{3} \mathrm{CL} 1\right)$ is a structurally novel protein in which a soluble chemokine-like domain is fused to a mucin stalk that extends through the cell membrane and into the cytoplasm (4). FK is expressed on activated endothelial cells (5), is upregulated by activators of protein kinase $\mathrm{C}(6)$, and has been detected in human atherosclerotic lesions (7). As a full-length transmembrane protein, FK acts as an adhesion molecule and efficiently captures cells under physiological flow conditions $(8,9)$. Cleavage of the FK mucin stalk close to the junction with the transmembrane domain produces a soluble form of FK $(4,10)$ that is a potent chemoattractant for monocytes and $\mathrm{T}$ cells (4). The ability of FK to both attract and arrest blood monocytes, as well as its presence in vascular wall cells, makes it an attractive candidate for playing a pivotal role in foam cell formation.

Received for publication March 28, 2002, and accepted in revised form December 17, 2002.

Address correspondence to: Israel F. Charo, Gladstone Institute of Cardiovascular Disease, P.O. Box 419100, San Francisco, California 94141-9100, USA. Phone: (415) 826-7500;

Fax: (415) 285-5632; E-mail: icharo@gladstone.ucsf.edu.

Christopher A. Haskell's present address is: Berlex Biosciences,

Richmond, California, USA.

Conflict of interest: The authors have declared that no conflict of interest exists.

Nonstandard abbreviations used: fractalkine (FK); smooth muscle cell (SMC); tyramide signal amplification (TSA);

$\beta$-glucuronidase ( $\beta$-GUS); fast-performance liquid chromatography (FPLC).
FK signals via activation of a seven-transmembrane domain, $\mathrm{G}$ protein-coupled receptor known as $\mathrm{CX}_{3} \mathrm{CR} 1$ (11). In humans, $\mathrm{CX}_{3} \mathrm{CR} 1$ is expressed predominantly on monocytes, T cells, and NK cells (11). To gain insight into the physiological roles of $\mathrm{FK}$, we recently used homologous recombination to delete $\mathrm{CX}_{3} \mathrm{CR} 1$ (12). Analysis of $\mathrm{CX}_{3} \mathrm{CR}^{-/-}$mice revealed that they rejected transplanted MHC class I/II mismatched hearts more slowly than did wild-type littermate controls, and that protection was associated with decreased infiltration by monocytes/macrophages and NK cells (12). To directly examine the role of $\mathrm{FK}$ and $\mathrm{CX}_{3} \mathrm{CR} 1$ in atherogenesis, we crossed $\mathrm{CX}_{3} \mathrm{CR}^{-/-}$mice with $a p o E^{-/-}$mice and quantified lesion development in the offspring fed a high-fat Western diet. Here we report that deletion of $\mathrm{CX}_{3} \mathrm{CR} 1$ affords significant protection from macrophage recruitment and atherosclerotic plaque formation.

\section{Methods}

Mice. $\mathrm{CX}_{3} \mathrm{CR}^{-/-}$, apoE $E^{-/-}$and $\mathrm{CX}_{3} \mathrm{CR}^{+/+}$, apoE $E^{-/-}$mice were generated by crossing $\mathrm{CX}_{3} \mathrm{CR} 1^{-/-}$mice (12) with apoE $E^{-/-}$mice (13) (N10 C57BL/6; The Jackson Laboratory, Bar Harbor, Maine, USA). Subsequent matings of pairs of $\mathrm{CX}_{3} \mathrm{CR}^{+/-}$, apoE $E^{-/-}$mice yielded animals that entered the study. All study mice were littermates and were approximately $92 \% \mathrm{C} 57 \mathrm{BL} / 6$ and $8 \% 129 / \mathrm{Sv}$, based on the number of backcrosses onto the C57BL/ 6 genetic background. Genotyping for $\mathrm{CX}_{3} \mathrm{CR} 1$ and apoE was done by PCR (12). All mice were housed in a specific pathogen-free facility.

The mice were weaned at 21 days of age and fed a normal rodent chow diet containing 4.5\% fat (Ralston Purina Co., St. Louis, Missouri, USA) for 2 weeks. At 5 weeks 
of age they were switched to a high-fat Western-type diet (0.15\% cholesterol, $21 \%$ anhydrous milk fat; Harlan Teklad Laboratory, Madison, Wisconsin, USA). Both males and females were included in the study. Mice were maintained on the high-fat diet for 5,10 , or 15 weeks and were weighed immediately before sacrifice.

Immunohistochemistry. To quantitate the cellular content of atherosclerotic lesions in the proximal aorta, we stained sections with antibodies for macrophages (MOMA-2 from BioSource International, Camarillo, California, USA, and CD11b from BD Pharmingen, San Diego California, USA), NK cells (clone 4D11; BD Pharmingen), endothelial cells (CD144, VE cadherin; BD Pharmingen), and smooth muscle cells (SMCs) ( $\alpha$-actin, clone 1A4; DAKO Corp., Glostrup, Denmark). SMCs were also delineated by staining elastin fibers using a Movat stain (14). Sections were air dried for 1 hour and then fixed in acetone for 10 minutes at $-20^{\circ} \mathrm{C}$ or in formalin (10\%) for 30 minutes at room temperature. For antibody staining, the endogenous peroxidase activity was neutralized with $\mathrm{H}_{2} \mathrm{O}_{2}(0.3 \% \mathrm{vol} / \mathrm{vol})$ for 10 minutes at room temperature and the sections were blocked with BSA (3\% wt/vol in PBS and $20 \mathrm{mM}$ glycine) for 60 minutes at room temperature. Cell type-specific or control antibodies were incubated overnight with the sections at 1:400 dilution in PBS with $20 \mathrm{mM}$ glycine at $4^{\circ} \mathrm{C}$. After washing, a goat antirat or a goat anti-hamster biotinylated secondary antibody (1:300 dilution; BD Pharmingen) was added, followed by streptavidin-horseradish peroxidase (BD Pharmingen). The signal was enhanced with a tyramide signal amplification (TSA) kit (NEL 702; NEN Life Science Products Inc., Boston, Massachusetts, USA) according to the manufacturer's protocol, and the sections were counterstained for nuclei with DAPI (Molecular Probes Inc., Eugene, Oregon, USA). For $\alpha$-actin, the MOM kit (Vector Laboratories Inc., Burlingame, California, USA) was used. FK was detected with a goat anti-mouse FK antibody (1:300 dilution; R\&D Systems Inc., Minneapolis, Minnesota, USA) that was raised against the amino-terminal domain of mouse FK and which does not cross-react with CD84 (15). A biotinylated secondary antibody (1:300 dilution; BD Pharmingen) was added, followed by streptavidin-horseradish peroxidase (BD Pharmingen). The signal was enhanced with the TSA kit NEL 702 (NEN Life Science Products Inc.) according to the manufacturer's protocol, with tetramethylrhodamine as the fluorophore. The specificity of this antibody was confirmed by blocking staining with soluble FK (R\&D Systems Inc.).

Colocalization of FK with cellular components of atherosclerotic lesions. Colocalization of FK with SMCs, endothelial cells, and macrophages was performed on randomly selected sections of the aortic sinus of C57BL/ 6 $a p o E^{-/-}$mice maintained on the Western diet for 10 or 15 weeks. To determine colocalization of FK with macrophages, a double immunostaining method was used. Tissue sections were stained for FK as described above, giving rise to red fluorescence. For detection of macrophages, a combination of three FITC-conjugated antibodies (F4/80, CD68, and MOMA-2; Serotec Inc., Raleigh, North Carolina, USA) was used, giving rise to green fluorescence. Images captured with a phycoerythrin filter (red fluorophore) were merged with images captured with an FITC filter (green fluorophore); colocalization of FK and macrophages was indicated by the resulting yellow color.

To quantify colocalization of CD $11 \mathrm{~b}^{+}$monocytes/ macrophages with FK, sections were stained for FK as described above and for CD11b using FITC-conjugated antibodies from BD Pharmingen (clone M1/70) and Serotec Inc. (clone 5C6). A total of 300 high-power fields were examined, and the number of CD $11 b^{+}$cells adjacent to FK was noted. FK intensity was scored on a scale of - to +++ .

Dissection of arteries, establishment of primary cell cultures, and RNA preparation. All procedures were performed under aseptic conditions using C57BL/6 apo $E^{-/-}$mice that had been maintained on the Western diet for 10 or 15 weeks. Primary endothelial cells were harvested by opening the thoracic and abdominal aortas with a longitudinal incision, placing the flattened vessel between two glass microscope slides, and pressing gently. Endothelial cells remained adhered to the glass after the vessel was removed, and RNA was extracted by the addition of Trizol solution. Staining with antibodies specific for SMC $\alpha$-actin, CD11b, and MOMA-2 confirmed that these preparations contained less than $1 \%$ SMCs and/or macrophages. To quantify FK expression in SMCs in vivo, we harvested aortic media as described by Schecter et al. (16). Briefly, the thoracic aorta was isolated and digested in HBSS containing $175 \mathrm{U} / \mathrm{ml}$ of type II collagenase (Worthington Biochemical Corp., Lakewood, New Jersey, USA) for 3-5 minutes. The adventitia was removed from the aortic media by grasping both tissues with forceps and gently pulling in opposite directions. Any remaining loosely adherent tissue was removed from the aortic media by gently scraping with a bent forceps. For extraction of total RNA, the aortic media was rinsed with DMEM, cut into small pieces, placed into Trizol solution, and snap frozen. To establish SMC cultures, aortic media preparations were further digested with a fresh solution of HBSS containing $175 \mathrm{U} / \mathrm{ml}$ type II collagenase and $0.25 \mathrm{mg} / \mathrm{ml}$ elastase (Sigma type I from porcine pancreas; SigmaAldrich, St., Louis, Missouri, USA), as described by Schecter et al. (16). Primary cultures of SMCs were grown in 20\% FCS/DMEM for the first 48 hours, followed by $10 \%$ FCS/DMEM. Incubation of primary cultures with antibodies specific for endothelial cells (CD144 and MECA-32) and monocyte/macrophage markers (CD11b, CD68, F4/80, and MOMA-2) confirmed that the cultures contained less than $1 \%$ endothelial cells and/or macrophages, respectively. To quantify FK expression in the aortic root, the heart and attached aorta were removed, the aortic roots were dissected out, and any remaining myocardial tissue was carefully removed using a stereo microscope. The aortic 

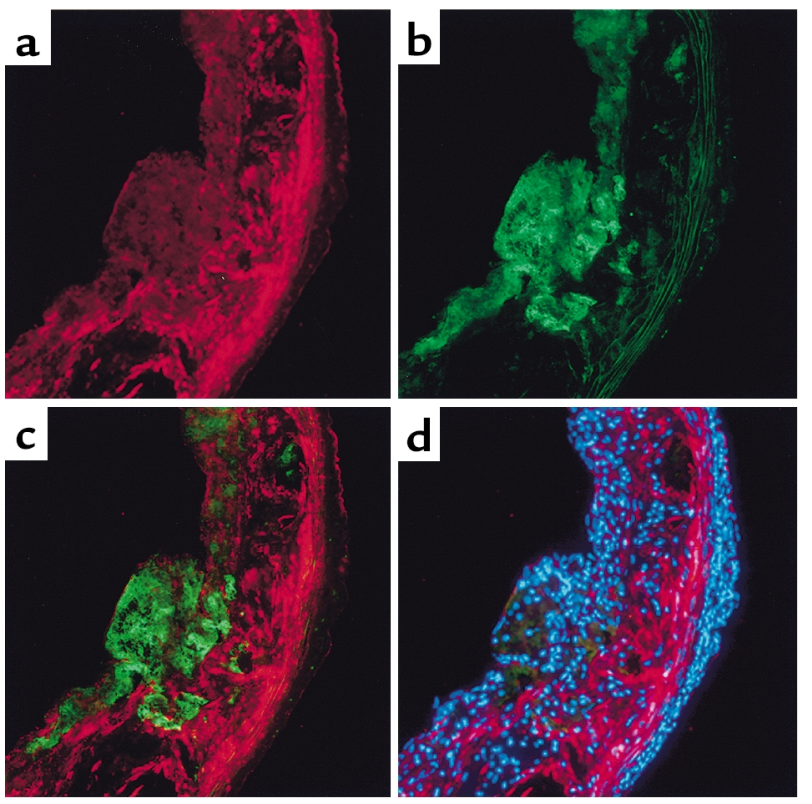

\section{Figure 1}

Immunolocalization of FK in atherosclerotic lesions. Mice lacking apoE ( $a p o E^{-/-}$mice) were maintained on the Western diet for 10 weeks. Serial sections were cut at the level of the aortic valve leaflets and incubated with antibodies. (a) Staining of FK (visualized as red). (b) Staining of macrophages (visualized as green). (c) Merged image of $\mathbf{a}$ and $\mathbf{b}$. (d) Nuclei were stained with DAPI (blue) and the image was captured with a multiband (DAPI/phycoerythrin/FITC) filter. Original magnification: $\times 200$.

root tissue was then cut into small pieces, placed into Trizol solution, and snap frozen. Bone marrow-derived macrophages were isolated as described by Fortier et al. and Kruisbeek et al. $(17,18)$ and cultured in DMEM supplemented with $20 \% \mathrm{FBS}, 2 \mathrm{mM}$ L-glutamine, $1 \mathrm{mM}$ sodium pyruvate, $2 \mathrm{mM}$ penicillin/streptomycin, and $30 \%$ L929 cell-conditioned media. The bone marrow-derived macrophages were analyzed after 8 days in culture, at which time they had acquired macrophagelike morphology and were greater than $99 \%$ positive for surface expression of MOMA-2, F4/80, and CD68.

Analysis of gene expression by real-time quantitative RT-PCR. Total RNA was extracted by a phenol/chloroform-based method (TRIzol reagent; Invitrogen Corp., Carlsbad, California, USA), following the manufacturer's instructions. To eliminate potential genomic DNA contamination, RNA samples were treated with DNase (4 U DNA-free; Ambion Inc., Houston, Texas, USA) in the presence of RNase inhibitor (RNaseOut; Invitrogen Corp.) at $37^{\circ} \mathrm{C}$ for 1 hour. RNAs were then further purified using RNeasy mini columns (QIAGEN Inc., Los Angeles, California, USA), and the concentration was determined using a sensitive nucleic acid dye binding assay (RiboGreen; Molecular Probes Inc., Eugene, Oregon, USA) according to the manufacturer's instructions. Real-time quantitative RT-PCR was used to quantify FK mRNA levels in homogenized murine tissue samples (medial SMCs, aortic roots, and endothelium) and in cultured murine cells (SMCs and bone marrow-derived macrophages). Total RNA (200 ng) was reverse transcribed in a $40-\mu \mathrm{l}$ reaction containing oligo(dT) ${ }_{12-18}$ primer and SuperScript II enzyme (Invitrogen Corp.). Complementary DNA was quantitatively analyzed for the expression of mouse FK by the fluorogenic 5'-nuclease PCR assay using an ABI Prism 7700 Sequence Detection System (Applied Biosystems, Foster City, California, USA). Specific primer probes for mouse FK were obtained from Applied Biosystems. Briefly, $5 \mu \mathrm{l}$ cDNA ( $25 \mathrm{ng}$ ) was amplified in the presence of $12.5 \mu \mathrm{l}$ TaqMan Universal PCR Master Mix (Applied Biosystems), $1.25 \mu$ l gene-specific probe and primers, and $6.25 \mu \mathrm{l}$ water. Samples underwent the following PCR protocol: $50^{\circ} \mathrm{C}$ for 2 minutes; $95^{\circ} \mathrm{C}$ for $10 \mathrm{~min}$ utes; and 40 cycles of $95^{\circ} \mathrm{C}$ for 15 seconds followed by $60^{\circ} \mathrm{C}$ for 1 minute. Relative expression levels were calculated by the comparative cycle threshold method as outlined in the manufacturer's technical bulletin. Measured RNA levels were normalized to $\beta$-glucuronidase $(\beta$-GUS) and expressed as a ratio of murine FK/ $\beta$-GUS. The primer pair sequences for $\beta$-GUS were $5^{\prime}$-CTCATCTGGAATTTCGCCGA-3' (forward) and 5'-GGCGAGTGAAGATCCCCTTC-3' (reverse). SYBR Green PCR master mix (Applied Biosystems, Warrington, United Kingdom) was used for detection of $\beta$-GUS cDNA.

Fast performance liquid chromatography analysis and lipid analysis. Mice were maintained on the Western diet for either 5 weeks or 10 weeks. Lipoproteins were fractionated by fast-performance liquid chromatography (FPLC) on a Superose 6 column (Amersham Biosciences, Newark, New Jersey, USA) as described (19). For lipid determinations, blood was collected by cardiac puncture from mice at the time of sacrifice, following an overnight fast. Plasma cholesterol levels were determined with Boehringer Mannheim kit no. 816302 (Boehringer

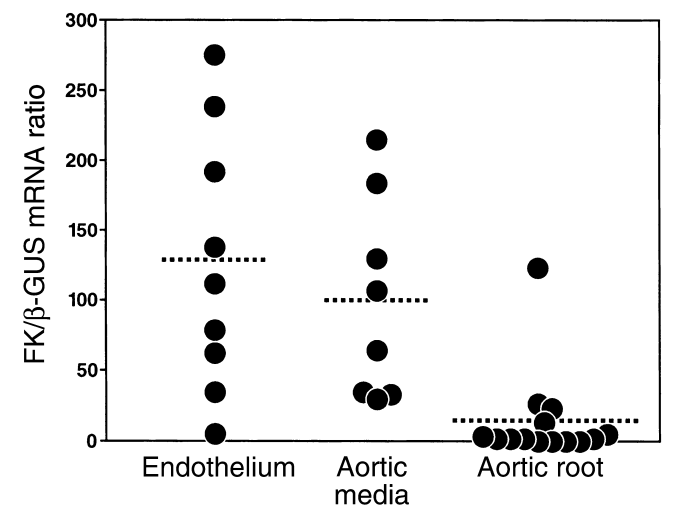

\section{Figure 2}

Determination ofFK mRNA in primary vascular tissues. Mice lacking apoE were maintained on the Western diet for 15 weeks. Thoracic and abdominal aortas were opened longitudinally, and the luminal endothelial cells ( $n=11$ mice), aortic media ( $n=8$ mice), and the aortic root ( $n=14$ mice) were isolated as described in Methods. Real-time PCR was performed to quantify FK mRNA expression, and the results are expressed as the mRNA FK/ $\beta$-GUS mRNA. Each data point represents the mean of duplicate measurements. 

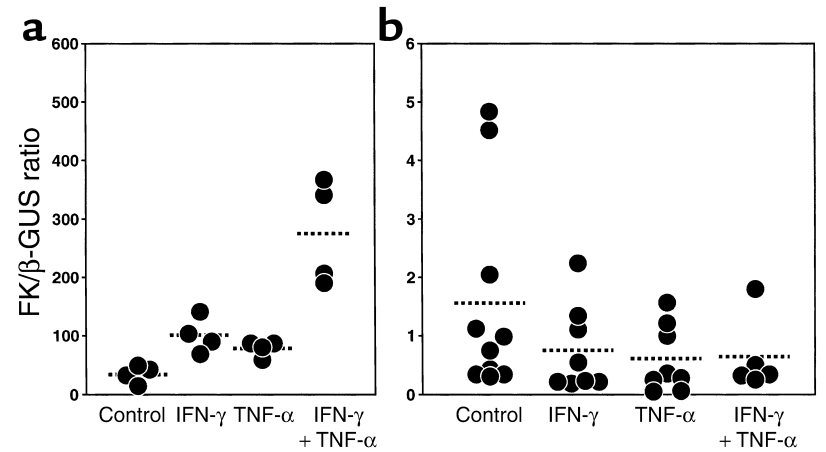

\section{Figure 3}

Determination of FK mRNA in SMCs and macrophages. Mice lacking apoE were maintained on the normal chow diet, and primary SMCs and bone marrow-derived macrophage cultures were established as described in Methods. (a) SMCs were incubated for 24 hours with IFN- $\gamma(20 \mathrm{ng} / \mathrm{ml})$, TNF- $\alpha(20 \mathrm{ng} / \mathrm{ml})$, or both cytokines, and FK mRNA levels were determined by quantitative real-time PCR, as described in the legend for Figure 2. (b) Bone marrow-derived macrophages (note $y$-axis scale change). SMC cultures were established from two different mice and were used before passage three. Bone marrow-derived macrophages were from three different donors and were used on day 8 . Each data point represents the mean of duplicate measurements.

Mannheim GmbH, Mannheim, Germany), and total plasma triglycerides were determined with a colorimetric assay (Abbott kit no. 1352; Abbott Laboratories, Abbott Park, Illinois, USA) as described by the manufacturer.

Statistical analysis. To analyze differences in the extent of atherosclerosis, lipid measurements, and body weights, Mann-Whitney U tests were performed using InStat 2.01 software (GraphPad Software Inc., San Diego, California, USA). $P$ values smaller than 0.05 were considered significant.

Atherosclerosis analysis. The degree of atherosclerosis was assessed by determining lesion sizes on both pinned-open aortas and serial cross sections through the aortic root, as described $(20,21)$. To quantify atherosclerosis along the entire aorta, the aortic tree was dissected out, cleaned of any adipose and connective tissue attached to the adventitia, and analyzed, essentially as described by Véniant et al. (21). Briefly, mice were perfused through a cannula inserted into the left ventricle with PBS followed by a fixative solution (10\% phosphate-buffered formalin, $7.5 \%$ sucrose, $20 \mu \mathrm{M}$ butylated hydroxytoluene, and $200 \mu \mathrm{M}$ EDTA, $\mathrm{pH}$ 7.4). The aorta was opened longitudinally along the ventral midline from the iliac arteries to the aortic root. After branching vessels were removed, the aorta was pinned out flat on a black wax surface. The lesions were stained with Sudan IV for 15 minutes, destained with $80 \%$ ethanol for 20 minutes, and then washed and stored in the fixative solution. To determine the extent of lesions on the pinned-open aortas, the amount of Sudan IV staining was quantified with color thresholding to delimit areas of staining. Aortic images were captured with a Polaroid digital camera (DMC1) mounted on a Leica MZ6 dissection microscope (Technical Instrument San Francisco, San Francisco, California, USA) and analyzed with Adobe Photoshop 6 software (Adobe Systems Inc., Mountain View, California, USA) and the Image Processing Tool Kit (Reindeer Games, Gainesville, Florida, USA) plug-ins. Three images of each aorta were captured and divided into three regions (arch, thorax, and abdomen) from which both surface and lesion areas were quantified. Data are reported as the percentage of the aortic surface covered by lesions (total surface area of the atherosclerotic lesions divided by the total surface area of the aorta, both in $\mu \mathrm{m}^{2}$ ).

For analysis of atherosclerotic lesions in the proximal aortic root, we examined eight $\mathrm{CX}_{3} \mathrm{CR}^{+/+}$, apo $\mathrm{E}^{-/-}$mice and eight $\mathrm{CX}_{3} \mathrm{CR}^{-/-}, \mathrm{apo} \mathrm{E}^{-/-}$mice after 10 weeks on the high-fat diet. The total aortic lesion areas of each of these eight mice were approximately equal to the mean of all $\mathrm{CX}_{3} \mathrm{CR}^{+/+}$, apo $E^{-/-}$and $\mathrm{CX}_{3} \mathrm{CR}^{-1^{--}}$, apo $\mathrm{E}^{-/-}$mice, respectively at the ten-week time point. The hearts were perfused for 30 minutes with fixative solution $(10 \%$ phosphate-buffered formalin, $7.5 \%$ sucrose, $20 \mu \mathrm{M}$ butylated hydroxytoluene, and $200 \mu \mathrm{M}$ EDTA, pH 7.4) and then equilibrated for a minimum of 4 hours in $20 \%$ sucrose before embedding in optimal cutting temperature media cryostat molds. Approximately 80 sections, $10 \mu \mathrm{m}$ thick, were cut through the proximal aorta, centered on the orifice of the left coronary artery. Every seventh section was stained with oil red $\mathrm{O}(0.5 \%$ in propylene glycol) for 4 hours and then counterstained with Mayer hematoxylin for 1 minute. Images were captured using a Nikon Eclipse 600 microscope and a SPOT-2 digital camera (Technical Instrument San Francisco).

\section{Figure 4}

Immunostaining of atherosclerotic lesions in $a p o E^{-/-}$mice. Mice were fed the Western-type high-fat diet for 10 weeks, and serial sections were cut through the proximal aorta and stained for FK (a), CD11b (b), or with Movat stain to visualize elastin (c). Original magnification: $\times 200$.
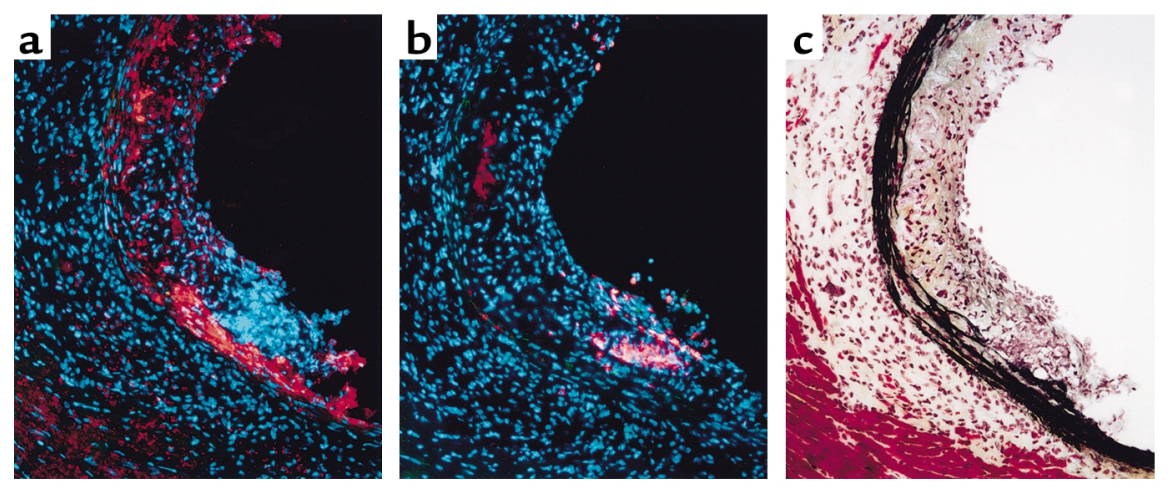
Table 1

Association of CD11 $b^{+}$cells with FK

\begin{tabular}{lccc}
\hline FK intensity & No. HPFs & No. CD11 b cells & $\begin{array}{c}\% \text { of total } \\
\text { CD11 } b^{+} \text {cells }\end{array}$ \\
- & 90 & 254 & $10 \%$ \\
+ & 81 & 425 & $17 \%^{\mathrm{A}}$ \\
++ & 91 & 807 & $33 \%^{\mathrm{A}}$ \\
+++ & 38 & 946 & $39 \%^{\mathrm{A}}$ \\
Total & 300 & 2,432 & $100 \%$
\end{tabular}

A total of 300 high-power fields (HPFs) chosen randomly from 40 sections through the aortic roots of apoE $E^{-/-}$mice $(n=8)$ on the Western diet for 10 weeks were examined. The sections included both lesional and non-lesional areas. A total of 2,432 CD11 $\mathrm{b}^{+}$cells were counted and graded for the intensity of FK expression in the immediately adjacent area. - denotes no detectable FK expression; + denotes weak FK expression, ++ denotes moderate FK expression, and +++ denotes intense FK expression. ${ }^{A} P<0.0001$ vs. areas with no detectable FK.

The extent of atherosclerosis was measured with color thresholding to delimit areas of oil red $\mathrm{O}$ staining as described above, and is reported as mean lesion area of the group of the sections.

\section{Results}

Expression of FK in atherosclerotic lesions. We first sought to determine whether FK was expressed in atherosclerotic lesions. We incubated aortic cross sections from $a p o E^{-/-}$mice on the high-fat Western diet for 10 weeks, with antibodies directed against the amino-terminal portion of FK. FK was easily detected in lesional areas (Figure 1a) but not in non-lesional areas of the aorta (data not shown). Analysis of serial sections revealed that FK expression was most intense on SMCs located directly beneath macrophages and that the macrophages themselves were only weakly positive (Figure 1). FK expression was also noted on the endothelial cells in lesional areas (Figure 1, a and c) and in areas that were devoid of cells (Figure 1d).

We next harvested the endothelium and the SMC media from the proximal aortas of $a p o E^{-/-}$mice on the high-fat Western diet for 15 weeks. As shown in Figure 2 , there was abundant expression of FK mRNA in both the endothelium and the aortic media, but not in the macrophage-rich aortic roots of these mice. Staining with antibodies specific to endothelial cells and to SMCs revealed that these primary cultures were greater than $99 \%$ pure (data not shown).
To determine the effects of cytokines on FK mRNA expression, we analyzed early-passage cultures of murine aortic SMCs and bone marrow-derived macrophages. As shown in Figure 3a, FK mRNA was easily detected in the SMC cultures and was dramatically upregulated by the combination of IFN- $\gamma$ and TNF- $\alpha$, two cytokines known to be present in atherosclerotic lesions. In agreement with the data from macrophage-rich aortic roots, there was very little FK mRNA present in the bone marrow-derived macrophages, and this was not augmented by the addition of IFN- $\gamma$ and TNF- $\alpha$ (Figure 3b; note parts $3 \mathrm{a}$ and $3 \mathrm{~b}$ show different $y$-axis scales).

We noted a correlation between the robust expression of FK on SMCs and the presence of adjacent CD11 $\mathrm{b}^{+}$ monocytes/macrophages, as illustrated in Figure 4. We quantified this observation by staining serial sections for FK and CD11b and grading the degree of FK expression

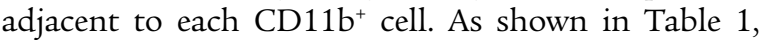
approximately $90 \%$ of all CD 11 b-positive cells were located directly adjacent to areas that stained for FK. Approximately $13 \%$ of the high-power fields contained areas that stained intensely for FK, yet these fields contained 39\% of the $\mathrm{CD} 11 \mathrm{~b}^{+}$cells detected in all high-power fields.

Atherosclerotic lesion formation in $\mathrm{CX}_{3} \mathrm{CR} 1$-deficient mice. To directly assess the importance of FK expression in atherosclerotic lesions, we crossed $a p o E^{-/-}$mice with mice deficient in $\mathrm{CX}_{3} \mathrm{CR} 1$, the receptor for $\mathrm{FK}$. $\mathrm{CX}_{3} \mathrm{CR} 1^{-/-}$, apoE $\mathrm{E}^{-/-}$and $\mathrm{CX}_{3} \mathrm{CR} 1^{+/+}$, apoE $\mathrm{E}^{-/-}$mice were placed on the high-fat Western diet for 5,10 , or 15 weeks. There were no significant differences in total cholesterol or triglycerides between the two groups (Table 2). Analysis of mice on the diet for 10 weeks revealed no differences between genotypes in their lipoprotein profiles as determined by FPLC (Figure 5). Very similar results were obtained with mice on the Western diet for 5 weeks (data not shown).

Lesion size was quantified in aortas pinned out and stained with Sudan IV. The results of this analysis revealed significant reductions in aortic coverage in the $\mathrm{CX}_{3} \mathrm{CR} 1^{-/-}$mice at each of the three timepoints (Figure $6 a)$. After 10 weeks on the Western diet, lesions covered an average of $6.7 \%$ of the total aorta in the $C X_{3} C R 1^{+/+}$ mice, compared with $3.4 \%$ in the $C X_{3} C R 1^{-/-}$mice. Lesions in the $C X_{3} C R 1^{+/+}$mice grew steadily with time, whereas lesion progression in the $C X_{3} C R 1^{-/-}$mice was

Table 2

Total cholesterol, triglycerides, and weights of mice on the Western diet

\begin{tabular}{|c|c|c|c|c|c|c|c|c|c|c|c|c|}
\hline \multirow[t]{2}{*}{ Genotype } & \multicolumn{4}{|c|}{5 weeks } & \multicolumn{4}{|c|}{10 weeks } & \multicolumn{4}{|c|}{15 weeks } \\
\hline & $\begin{array}{c}\text { Male } \\
\text { weight }(\mathrm{g})\end{array}$ & $\begin{array}{c}\text { Female } \\
\text { weight }(\mathrm{g})\end{array}$ & $\begin{array}{c}\mathrm{TC} \\
\mathrm{mg} / \mathrm{dl}\end{array}$ & $\begin{array}{c}\text { TG } \\
\mathrm{mg} / \mathrm{dl}\end{array}$ & $\begin{array}{c}\text { Male } \\
\text { weight }(\mathrm{g})\end{array}$ & $\begin{array}{c}\text { Female } \\
\text { weight }(\mathrm{g})\end{array}$ & $\begin{array}{c}\mathrm{TC} \\
\mathrm{mg} / \mathrm{dl}\end{array}$ & $\begin{array}{c}\text { TG } \\
\mathrm{mg} / \mathrm{dl}\end{array}$ & $\begin{array}{c}\text { Male } \\
\text { weight }(\mathrm{g})\end{array}$ & $\begin{array}{c}\text { Female } \\
\text { weight }(\mathrm{g})\end{array}$ & $\begin{array}{c}\mathrm{TC} \\
\mathrm{mg} / \mathrm{dl}\end{array}$ & $\begin{array}{c}\mathrm{TG} \\
\mathrm{mg} / \mathrm{d}\end{array}$ \\
\hline \multirow[t]{2}{*}{$\begin{array}{l}C X_{3} C R 1^{+/+} \\
\text {apoE }\end{array}$} & $\begin{array}{c}26.3 \pm \\
0.5\end{array}$ & $\begin{array}{c}21.2 \pm \\
1.2\end{array}$ & $\begin{array}{c}926 \pm \\
152\end{array}$ & $\begin{array}{c}109 \pm \\
24\end{array}$ & $\begin{array}{c}33.6 \pm \\
5.3\end{array}$ & $\begin{array}{c}25.7 \pm \\
4.9\end{array}$ & $\begin{array}{c}870 \pm \\
108\end{array}$ & $\begin{array}{c}93 \pm \\
39\end{array}$ & $\begin{array}{c}35.2 \pm \\
6.1\end{array}$ & $\begin{array}{c}23.5 \pm \\
2.3\end{array}$ & $\begin{array}{c}905 \pm \\
156\end{array}$ & $\begin{array}{c}81 \pm \\
41\end{array}$ \\
\hline & $n=3$ & $n=4$ & $n=7$ & $n=7$ & $n=6$ & $n=4$ & $n=10$ & $n=10$ & $n=9$ & $n=7$ & $n=16$ & $n=16$ \\
\hline \multirow[t]{2}{*}{$\begin{array}{l}C X_{3} C R^{-/-} \\
\text {apo } E^{-/-}\end{array}$} & $\begin{array}{c}27.9 \pm \\
3\end{array}$ & $\begin{array}{c}22.8 \pm \\
1.9\end{array}$ & $\begin{array}{c}837 \pm \\
95\end{array}$ & $\begin{array}{c}89 \pm \\
39\end{array}$ & $\begin{array}{c}28.3 \pm \\
3.5\end{array}$ & $\begin{array}{c}22.2 \pm \\
2.1\end{array}$ & $\begin{array}{c}734 \pm \\
249\end{array}$ & $\begin{array}{c}80 \pm \\
42\end{array}$ & $\begin{array}{c}33.1 \pm \\
4.3\end{array}$ & $\begin{array}{c}25.7 \pm \\
2.1\end{array}$ & $\begin{array}{c}843 \pm \\
152\end{array}$ & $\begin{array}{c}82 \pm \\
28\end{array}$ \\
\hline & $n=12$ & $n=5$ & $n=18$ & $n=18$ & $n=3$ & $n=10$ & $n=13$ & $n=13$ & $n=10$ & $n=16$ & $n=26$ & $n=26$ \\
\hline
\end{tabular}

Data are presented as mean \pm SD. TC, total cholesterol; TG, triglycerides. 


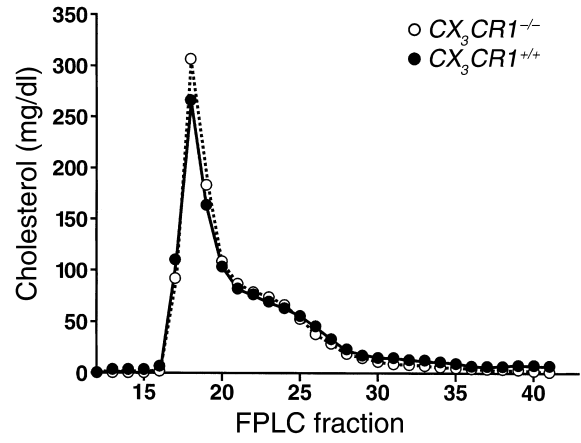

Figure 5

Lipoprotein analysis. Mice were maintained on a Western-type highfat diet for 10 weeks. Plasma was pooled, the lipoproteins were fractionated by FPLC, and the cholesterol content of each fraction was determined as described in Methods. Plasma from six $C X_{3} C R 1^{-1-}$ and six $C X_{3} C R 1^{+/+}$mice was pooled.

markedly attenuated. After 15 weeks on the diet, $10.9 \%$ of the aorta in the wild-type mice was covered by lesions, compared with $6.9 \%$ in the $\mathrm{CX}_{3} \mathrm{CR}^{-/-}$mice, representing a $36 \%$ reduction $(P<0.002)$.

The absence of $\mathrm{CX}_{3} \mathrm{CR} 1$ retarded lesion development in both the aortic arch (Figure 6b) and thoracic/ abdominal sections of the aorta (Figure 6c), though the difference was less pronounced in the arch.

To further examine atherosclerotic lesions in the arch area, we dissected out the hearts of eight $C X_{3} C R 1^{+/+}$and eight $C X_{3} C R 1^{-/-}$mice, all of whom had comparable Sudan IV staining of the entire aorta. Serial sections were stained with oil red $\mathrm{O}$ and lesion size was quantified by capturing digital images. As shown in Figure 7, there was a significant reduction in mean lesion area in the $\mathrm{CX}_{3} \mathrm{CR} 1^{-/-}$mice $(-32 \%, P<0.007)$. Taken together, these data indicate that, compared with wild-type mice, $\mathrm{CX}_{3} \mathrm{CR}^{-/-}$mice have reduced lesion areas and thickness at each of the three timepoints examined.

In the mouse, $\mathrm{CX}_{3} \mathrm{CR} 1$ is expressed primarily on monocytes/macrophages and NK cells. Therefore, we next asked whether $\mathrm{CX}_{3} \mathrm{CR}^{-/-}$mice had reduced numbers of macrophages in their plaques. As shown in Figure 8, the absence of $\mathrm{CX}_{3} \mathrm{CR} 1$ resulted in a $40 \%(P<0.005)$ decrease in MOMA-2 staining after 10 weeks on the Western diet. Only occasional NK cells were detected in both wild-type and $C X_{3} C R 1^{-/-}$mice (data not shown).

\section{Discussion}

The seminal studies of Ross et al. (3) in non-human primates and Gerrity et al. in swine (2) demonstrated that circulating blood monocytes are the precursors of the lipid-laden macrophages that are the hallmark of early atherosclerotic lesions. How the monocytes attached to the endothelium and then migrated into the vessel wall, however, was not clear. The past decade has seen a rapid increase in our understanding of leukocyte migration throughout the body, with the identification of approximately 50 chemokines and their cognate receptors on hematopoietic cells. Use of homologous recombination to delete specific chemokines or their receptors has revealed a critical role for $\mathrm{MCP}-1$ and its receptor, CCR2, in three different murine models of atherosclerosis $(20$, 22-24). In addition, recent studies have provided evidence that IL-8, a chemokine previously thought to primarily attract neutrophils, is also chemotactic for monocytes (25) and contributes to their recruitment to atherosclerotic lesions $(26,27)$. In this paper we provide evidence that FK, a chemokine with unusual properties, is highly expressed in early lesions and plays an important functional role in atherogenesis.

FK is the first member of a novel group of chemokines. Its unique architecture and prominent expression in the central nervous system $(10,28)$ immediately suggested important functions for this cytokine. However, phenotypes for both $\mathrm{FK}$ and $\mathrm{CX}_{3} \mathrm{CR} 1$ knockouts have been sub-
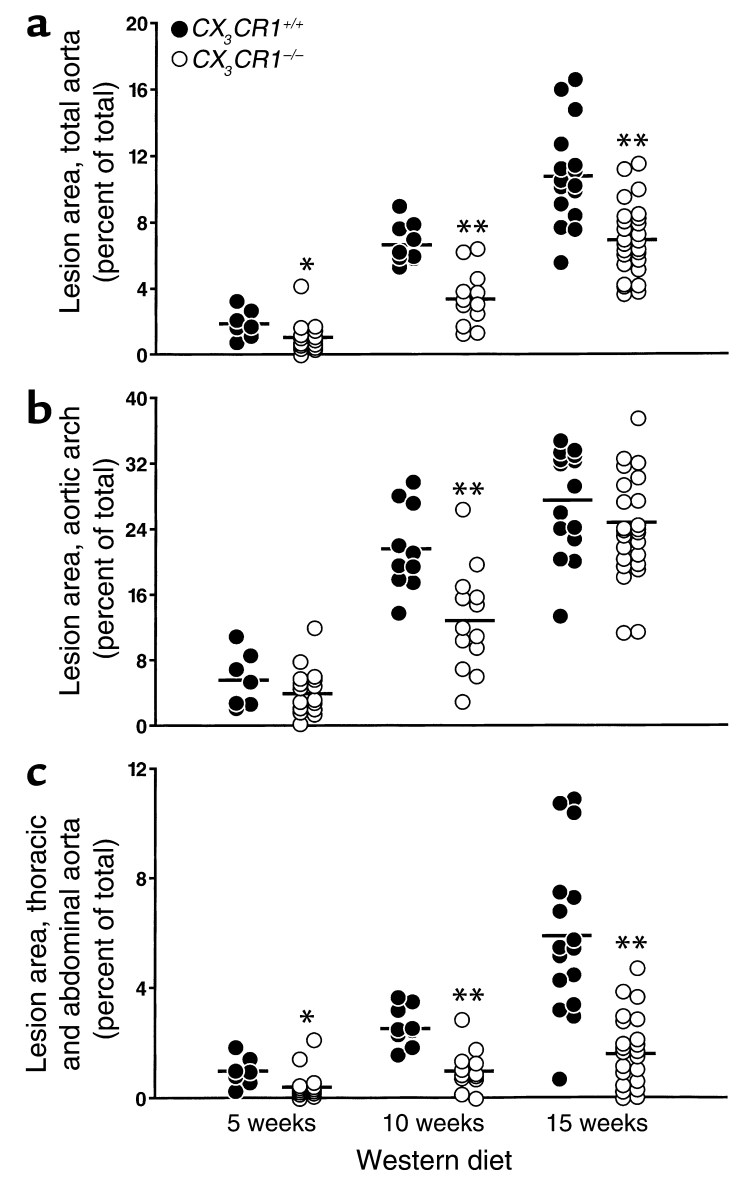

Figure 6

Atherosclerotic lesion areas in $\mathrm{CX}_{3} \mathrm{CR} 1^{+/+}, \mathrm{apoE}^{-/-}$and $\mathrm{CX}_{3} \mathrm{CR} 1^{-/-}$, $a p o E^{-/-}$mice fed the Western diet for 5,10 , or 15 weeks. Each symbol depicts the percentage of the aorta that stained for lipid with Sudan IV in a single mouse. (a) Total aorta. Lesions in the $C X_{3} C R 1^{-/-}$mice were significantly smaller than in $\mathrm{CX}_{3} C R 1^{+/+}$mice at each timepoint (43\%, $49 \%$, and $36 \%$ reduced at 5,10 , and 15 weeks, respectively). (b) Aortic arch. Lesions were smaller in the $\mathrm{CX}_{3} \mathrm{CR} 1^{-1-}$ mice at each of the timepoints $(29 \%, 40 \%$, and $11 \%$ reduced at 5,10 , and 15 weeks, respectively). (c) Thoracic and abdominal aorta. Lesions were smaller in the $C X_{3} C R 1^{-1-}$ mice at each of the timepoints (56\%, 60\%, and $72 \%$ reduced at 5,10 , and 15 weeks, respectively). The horizontal bars represent the mean values for the group. ${ }^{*} P \leq 0.02,{ }^{*} P \leq 0.002$ vs. wild type. 


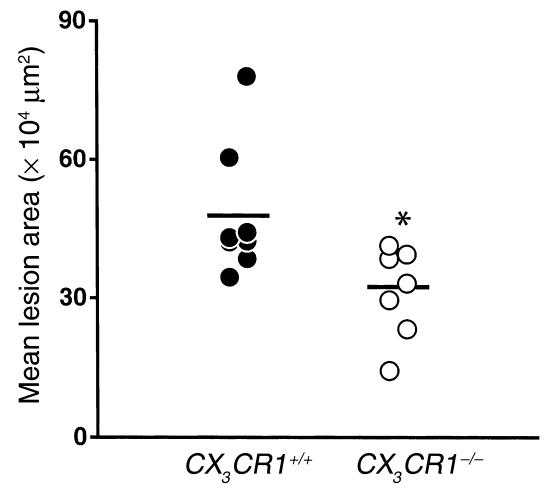

\section{Figure 7}

Quantitation of atherosclerosis in the aortic root area. $C X_{3} C R 1^{+/+}$, $a p o E^{-/-}$and $\mathrm{CX}_{3} C R 1^{-/-}$, apo $E^{-/-}$mice were fed the Western diet for 10 weeks, and the degree of atherosclerosis was determined by staining serial $10-\mu \mathrm{m}$ cross sections through the aortic root with oil red $\mathrm{O}$. Lesion area was quantified by digital morphometry. Each symbol represents the mean total lesion area in a single mouse, and the horizontal bar represents the mean of the group. The $\mathrm{CX}_{3} C R 1^{-1-}$ mice $(n=8)$ had significantly smaller total lesion areas $\left(32 \%\right.$ smaller, $\left.{ }^{*} P=0.007\right)$ than the $C X_{3} C R 1^{+/+}$mice $(n=8)$.

tle. In the case of FK null mice, Cook et al. (29) reported normal development and normal responses in several models of induced inflammation, including experimental peritonitis, delayed-type hypersensitivity, enterocolitis, and infection with Listeria monocytogenes. In $\mathrm{CX}_{3} \mathrm{CR} 1$ knockouts, Jung et al. (30) found normal responses to peritoneal inflammation, normal dendritic cell migration and function, a normal response to facial nerve injury, and no evidence of abnormal interactions between microglia and neurons. Haskell et al. (12) found that $\mathrm{CX}_{3} \mathrm{CR}^{-/-}$mice were indistinguishable from wild-type mice in models of glomerulonephritis, experimental autoimmune encephalitis, and peritonitis induced by thioglycollate. However, in this study, the $\mathrm{CX}_{3} \mathrm{CR}^{-/-}$mice had significant impairment in the rejection of heterotopically transplanted hearts, most likely due to decreased recruitment of NK cells (12). The current study provides evidence that FK recruits monocytes/macrophages into early atherosclerotic lesions and is the most robust phenotype described thus far for either the ligand or receptor knockout of this chemokine.

FK expression was prominent in macrophage-rich areas of the lesions, consistent with the analysis of human atherosclerotic lesions by Greaves et al. (7). However, the macrophages themselves stained only weakly for FK, and quantitative PCR analysis showed that they contained much less FK mRNA than did either endothelial cells or SMCs. Furthermore, in $a p o E^{-/-}$mice, quantitative PCR analysis of the aortic roots, an area that is very rich in macrophages, also revealed very low levels of FK mRNA. Taken together, these data indicate that macrophages are unlikely to be the primary source of FK in atherosclerotic lesions. Using in vitro studies, Ludwig et al. (31) reported that human SMCs express FK after treatment with IFN- $\gamma$. We have confirmed this result, and show that the combination of IFN- $\gamma$ and TNF- $\alpha$, two cytokines that are known to be present in atherosclerotic plaques, dramatically upregulates FK expression in murine SMCs but not in macrophages.

We noted that FK staining was not uniform, and that SMCs located directly beneath lesional macrophages expressed high levels of FK. Furthermore, CD11b ${ }^{+}$ macrophages were often found in close association with SMCs that expressed the highest levels of FK. Earlier studies have shown that newly recruited CD11b monocytes/macrophages tend to be found in the shoulder areas rather than in the center of atherosclerotic lesions, and that $\mathrm{CD} 11 \mathrm{~b}$ is downregulated as monocytes differentiate into macrophages (32). Taken together, these data are consistent with a model in which soluble FK, released from the surface of activated SMCs and/or endothelial cells by the proteolytic action of tumor-necrosis factor$\alpha$-converting enzyme (33), plays a direct role in recruiting monocytes/macrophages into developing lesions.

Earlier studies by our group $(20,23)$ and others $(22,24$, 26) have provided evidence that MCP- 1 and IL- 8 play important functional roles in atherogenesis, and it is reasonable to ask what function FK might be serving that is not already being performed by these two chemokines. The individual deletions of MCP-1 $(22,23)$, CCR2 (20, 24), the IL-8 receptor (26), or $\mathrm{CX}_{3} \mathrm{CR} 1$ each result in at least a 50\% decrease in atherosclerotic lesion area, suggesting that each of these chemokines cannot be acting completely independently. Nor can each be providing completely redundant functions. We therefore favor a model in which FK, MCP-1, and IL-8 act in concert to recruit circulating monocytes into the subendothelial space. In this model, FK and MCP-1 can be envisioned acting sequentially such that full-length $\mathrm{FK}$, along with VCAM-1 and ICAM-1, serves to capture flowing monocytes, which then migrate along an MCP-1 gradient into the subendothelial space. Soluble FK may also serve as a chemoattractant, and data presented herein provide evi-

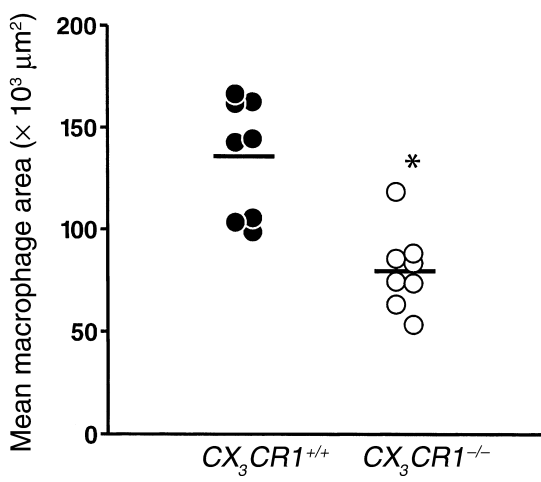

\section{Figure 8}

Macrophage infiltration of the aortic sinus in $\mathrm{CX}_{3} \mathrm{CR} 1^{+/+}, \mathrm{apoE} \mathrm{E}^{-/-}$and $\mathrm{CX}_{3} C R 1^{-/-}$, apoE $E^{-/-}$mice fed the Western diet for 10 weeks. Sections from the aortic sinus were stained for macrophages with MOMA-2 and quantified by digital morphometry. $C X_{3} C R 1^{+/+}$mice had significantly more MOMA-2 staining than the $C X_{3} C R 1^{-/-}$mice (40\% more, $\left.{ }^{*} P \leq 0.001\right)$. Each symbol represents a single mouse, and the horizontal bar represents the mean value for each group. 
dence that newly recruited monocytes are indeed preferentially found in FK-rich areas. Further evidence for the notion that chemokines can perform both chemoattractant and adhesive functions in atherogenesis comes from the work of Huo et al., who showed that IL-8 captures flowing monocytes in the mouse carotid artery (27). Elucidation of the relative contributions of full-length and soluble FK to atherogenesis will likely require the creation of mice in which FK is mutated to a noncleavable form.

In humans, a polymorphism in $\mathrm{CX}_{3} \mathrm{CR} 1$ has been identified at amino acid 249 (V249I) that results in decreased binding of FK (34). Two recent reports show that this common variant is protective for coronary artery disease and endothelial cell dysfunction $(34,35)$. Taken together with the findings presented herein, these data suggest that FK-dependent monocyte/macrophage capture and recruitment are important functional mechanisms in the pathogenesis of human atherosclerosis and provide support for the identification of $\mathrm{CX}_{3} \mathrm{CR} 1$ as a potentially important target for cardiovascular therapeutics.

In summary, we have found prominent expression of FK in SMCs located in macrophage-rich areas of atherosclerotic plaques in $\mathrm{apoE}^{-/-}$mice on the high-fat Western diet. Deletion of $\mathrm{CX}_{3} \mathrm{CR} 1$, the receptor for $\mathrm{FK}$, afforded significant protection from both macrophage recruitment to the vessel wall and the subsequent development of atherosclerotic lesions. These data provide a mechanistic basis for recent observations that patients with a common polymorphism in $\mathrm{CX}_{3} \mathrm{CR} 1$ have a decreased incidence of coronary artery disease, and suggest that therapeutics that interrupt $\mathrm{FK}$ binding to $\mathrm{CX}_{3} \mathrm{CR} 1$ might be beneficial in the treatment of cardiovascular disease.

\section{Acknowledgments}

This work was funded in part by NIH grants HL-63894 and HL-52773 to I.F. Charo. We thank Sarah Slaymaker for expert assistance with the real-time PCR experiments. We also thank John Carroll, Jack Hull, and Chris Goodfellow for preparation of the figures, Gary Howard for editorial assistance, and Naima Contos for manuscript preparation.

1. Ross, R. 1995. Cell biology of atherosclerosis. Annu. Rev. Physiol. 57:791-804.

2. Gerrity, R.G. 1981. The role of the monocyte in atherogenesis. I. Transition of blood-borne monocytes into foam cells in fatty lesions. Am. J. Pathol. 103:181-190

3. Faggiotto, A., Ross, R., and Harker, L. 1984. Studies of hypercholesterolemia in the nonhuman primate. I. Changes that lead to fatty streak formation. Arteriosclerosis. 4:323-340.

4. Bazan, J.F., et al. 1997. A new class of membrane-bound chemokine with a $\mathrm{CX}_{3}$ C motif. Nature. 385:640-644.

5. Harrison, J.K., et al. 1999. Inflammatory agents regulate in vivo expression of fractalkine in endothelial cells of the rat heart. J. Leukoc. Biol. 66:937-944.

6. Pan, Y., et al. 1997. Neurotactin, a membrane-anchored chemokine upregulated in brain inflammation. Nature. 387:611-617.

7. Greaves, D.R., et al. 2001. Linked chromosome $16 \mathrm{q} 13$ chemokines, macrophage-derived chemokine, fractalkine, and thymus- and activationregulated chemokine, are expressed in human atherosclerotic lesions. Arterioscler. Thromb. Vasc. Biol. 21:923-929.

8. Haskell, C.A., Cleary, M.D., and Charo, I.F. 2000. Unique role of the chemokine domain of fractalkine in cell capture. Kinetics of receptor dissociation correlate with cell adhesion. J. Biol. Chem. 275:34183-34189.

9. Fong, A.M., et al. 1998. Fractalkine and $\mathrm{CX}_{3} \mathrm{CR} 1$ mediate a novel mechanism of leukocyte capture, firm adhesion, and activation under physiologic flow. J. Exp. Med. 188:1413-1419.

10. Harrison, J.K., et al. 1998. Role for neuronally derived fractalkine in mediat- ing interactions between neurons and CX3CR1-expressing microglia. Proc. Natl. Acad. Sci. USA. 95:10896-10901.

11. Imai, T., et al. 1997. Identification and molecular characterization of fractalkine receptor $\mathrm{CX}_{3} \mathrm{CR} 1$, which mediates both leukocyte migration and adhesion. Cell. 91:521-530.

12. Haskell, C.A., et al. 2001. Targeted deletion of $\mathrm{CX}_{3} \mathrm{CR} 1$ reveals a role for fractalkine in cardiac allograft rejection. J. Clin. Invest. 108:679-688. doi:10.1172/JCI200112976.

13. Plump, A.S., et al. 1992. Severe hypercholesterolemia and atherosclerosis in apolipoprotein E-deficient mice created by homologous recombination in ES cells. Cell. 71:343-353

14. Johnson, J.L., and Jackson, C.L. 2001. Atherosclerotic plaque rupture in the apolipoprotein E knockout mouse. Atherosclerosis. 154:399-406.

15. Lucas, A.D., et al. 2001. The transmembrane form of the CX3CL1 chemokine fractalkine is expressed predominantly by epithelial cells in vivo. Am. J. Pathol. 158:855-866.

16. Schecter, A.D., et al. 1997. Tissue factor expression in human arterial smooth muscle cells. TF is present in three cellular pools after growth factor stimulation. J. Clin. Invest. 100:2276-2285.

17. Fortier, A.H., and Falk, L.A. 2002. Isolation of murine macrophages. In Current protocols in immunology. J.E. Coligan, A.M. Kruisbeek, D.M. Margulies, E.M. Shevach, and W. Strober, editors. John Wiley and Sons. New York, New York, USA. [Book online.] 14. Unit 14.1. Basic protocol 2. http://www.mrw2.interscience.wiley.com/cponline/tserver.dll?command $=$ doGetDoc\&sUI $=\&$ database $=$ CP\&useScheme $=$ WIS_Framed.Scheme\&get Doc $=$ cp_cpim_fs.html.

18. Kruisbeek, A.M. 2002. Isolation of mononuclear cell populations. In Current protocols in immunology. J.E. Coligan, A.M. Kruisbeek, D.M. Margulies, E.M. Shevach, and W. Strober, editors. John Wiley and Sons. New York, New York, USA. [Book online.] 3. Section 1. Unit 3.1. http:// www.mrw2.interscience.wiley.com/cponline/tserver.dll? command=doGetDoc\&sUI $=\&$ database $=$ CP\&useScheme $=$ WIS_Framed.Scheme\&get Doc $=$ cp_cpim_fs.html

19. Raffaï, R.L., and Weisgraber, K.H. 2002. Hypomorphic apolipoprotein E mice. A new model of conditional gene repair to examine apolipoprotein $\mathrm{E}$ mediated metabolism. J. Biol. Chem. 277:11064-11068.

20. Boring, L., Gosling, J., Cleary, M., and Charo, I.F. 1998. Decreased lesion formation in CCR2 ${ }^{-/-}$mice reveals a role for chemokines in the initiation of atherosclerosis. Nature. 394:894-897.

21. Véniant, M.M., et al. 2000. Defining the atherogenicity of large and small lipoproteins containing apolipoprotein B100. J. Clin. Invest. 106:1501-1510.

22. Gu, L., et al. 1998. Absence of monocyte chemoattractant protein-1 reduces atherosclerosis in low density lipoprotein receptor-deficient mice. Mol. Cell. 2:275-281.

23. Gosling, J., et al. 1999. MCP-1 deficiency reduces susceptibility to atherosclerosis in mice that overexpress human apolipoprotein B. J. Clin. Invest. 103:773-778

24. Dawson, T.C., Kuziel, W.A., Osahar, T.A., and Maeda, N. 1999. Absence of $\mathrm{CC}$ chemokine receptor- 2 reduces atherosclerosis in apolipoprotein E-deficient mice. Atherosclerosis. 143:205-211.

25. Gerszten, R.E., et al. 1999. MCP-1 and IL-8 trigger firm adhesion of monocytes to vascular endothelium under flow conditions. Nature. 398:718-723.

26. Boisvert, W.A., Santiago, R., Curtiss, L.K., and Terkeltaub, R.A. 1998. A leukocyte homologue of the IL- 8 receptor CXCR-2 mediates the accumulation of macrophages in atherosclerotic lesions of LDL receptor-deficient mice. J. Clin. Invest. 101:353-363.

27. Huo, Y., et al. 2001. The chemokine KC, but not monocyte chemoattractant protein-1, triggers monocyte arrest on early atherosclerotic endothelium. J. Clin. Invest. 108:1307-1314.

28. Hughes, P.M., Botham, M.S., Frentzel, S., Mir, A., and Perry, V.H. 2002. Expression of fractalkine (CX3CL1) and its receptor, CX3CR1, during acute and chronic inflammation in the rodent CNS. Glia. 37:314-327.

29. Cook, D.N., et al. 2001. Generation and analysis of mice lacking the chemokine fractalkine. Mol. Cell. Biol. 21:3159-3165.

30. Jung, S., et al. 2000. Analysis of fractalkine receptor $\mathrm{CX}_{3} \mathrm{CR} 1$ function by targeted deletion and green fluorescent protein reporter gene insertion. $\mathrm{Mol}$. Cell. Biol. 20:4106-4114.

31. Ludwig, A., Berkhout, T., Moores, K., Groot, P., and Chapman, G. 2002. Fractalkine is expressed by smooth muscle cells in response to IFN- $\gamma$ and TNF- $\alpha$ and is modulated by metalloproteinase activity. J. Immunol. 168:604-612.

32. Gray, J.L., and Shankar, R. 1995. Down regulation of CD11b and CD18 expression in atherosclerotic lesion-derived macrophages. Am. Surg. 61:674-680.

33. Tsou, C.-L., Haskell, C.A., and Charo, I.F. 2001. Tumor necrosis factor- $\alpha$-converting enzyme mediates the inducible cleavage of fractalkine. J. Biol. Chem. 276:44622-44626.

34. Moatti, D., et al. 2001. Polymorphism in the fractalkine receptor CX3CR1 as a genetic risk factor for coronary artery disease. Blood. 97:1925-1928.

35. McDermott, D.H., et al. 2001. Association between polymorphism in the chemokine receptor CX3CR1 and coronary vascular endothelial dysfunction and atherosclerosis. Circ. Res. 89:401-407. 